\title{
Permeating the social justice ideals of equality and equity within the context of Early Years: Challenges for leadership in multi-cultural and mono-cultural primary schools
}

\author{
Malini Mistry \& Krishan Sood \\ University of Bedfordshire, UK \& Nottingham Trent University, UK
}

\begin{abstract}
The ideology and commitment of social justice principles is central to Early Years practice, however, the term social justice in education is complex and remains contested. This paper explores the ideology of social justice through links between equality and equity and how it is embedded within Early Years, and what remain the potential challenges for leadership. Interviews in English multi-cultural and mono-cultural primary schools were conducted. Findings showed that the ideology of social justice, equality and equity was interpreted differently. Multi-cultural schools appear to use a greater variety of activities to embed social justice principles that involved their diverse communities more to enrich the curriculum. In mono-cultural schools leadership had to be more creative in promoting equality and equity given the smaller proportion of their diverse pupil and staff population. Tentative conclusions suggest that the vision for permeating equality and equity in Early Years, at best, is at early stages.
\end{abstract}

Key words: Early Years, equality, equity, primary multi-cultural/mono-cultural schools, leadership 


\section{Introduction}

The Early Years Foundation Stage (EYFS) encompasses four main principles that shapes practice in settings and consists of: understanding that every child is a unique child, children learn to be independent through positive relationships, children learn and develop in enabling environments, and the understanding that children learn in different ways and at different rates (DfE, 2012: Online). From September 2012 a revised EYFS became statutory in England for all government registered settings for children aged between birth and five. This revised framework came as a result of the Tickell Review in 2011 which was a Coalition government initiated independent review of the Early Years curriculum which aimed first, to reduce the current level of paperwork carried out by simplifying assessment for children at the end of the reception in school and second, to better support children's early learning (DfE, 2011: Online). There is sparse literature on how equality and equity permeates the Early Years curriculum, and what is published focuses importantly on developing children's language and identities (Issa and Hatt, 2013: 8). There is increasing interest to school leaders and practitioners (Bell and Stevenson, 2006: 139) on the issue of diversity, equity and social justice within Early Years, and we develop our thinking on these issues through this investigation. The focus of the paper is to explore the way equality and equity permeates into Early Years, and what remain the challenges for leadership, and are analysed next.

\section{Literature}

In 2008, the government introduced the EYFS framework which was developmentally orientated, and specified a number of Early Learning Goals (ELG's) to be achieved by children by the end of their reception year at school (aged 5yrs) (DCSF, 2008). There is a normative assumption that all children develop and progress sequentially regardless of their socio-cultural or minority ethnic background or earlier educational experiences. So the real decision-making for implementation by primary schools should be based on children's individual needs and contexts rather than any directives from the government.

We believe that leadership, at all levels of the school system, must hold the principles of social justice and the valuing of diversity, equality and equity (Coleman, and Glover, 2010: 6). We start by clarifying what we mean by these terms. 'Diversity' has 'many and different' meanings (Coleman and Glover, 2010: 6), but from a legislative stance, it addresses 
nine 'equality characteristics' currently protected in UK law: Age, Disability, Gender Reassignment, Marriage and Civil Partnership, Pregnancy and Maternity, Race, Religion or Belief, Sex and Sexual Orientation. Celebrating difference (Lumby and Coleman, 2007; Jehn et al., 2008), valuing diversity (Coleman and Glover, 2010) and minimising the impact of discrimination (Fiske and Lee, 2008) lie at the heart of understanding diversity.

We explore the concept of social justice, equality and equity through the notion of well-being next. It could be argued that Early Years plays a powerful role in developing the social and emotional health, and therefore, the well-being of an individual, associated with cognitive achievement (Fullan, 2007). As practitioners and leaders it is our professional calling developed from our personal values of social justice that we take into account our responsibilities to the future generation (Gardner, 2006). In promoting the well-being and happiness of an individual, Burchardt (2007) argues that happiness is central to the evaluation of social justice. In a somewhat crude representation of how equality and equity are deemed to be two powerful components of social justice could well lead to well-being and happiness, West-Burnham and Chapman (2008) has shown that we need to demonstrate a commitment to equality and equity. This may well mean allegiance to a collective value system of society where ethical and moral dimensions to social justice are demonstrated.

Equality may not be enough. Here, we define equality as every human being's absolute and equal right to common dignity and parity of esteem and entitlement to access the benefits of society in equal terms. In contrast, equity is where every human being has a right to benefit from the outcomes of society on the basis of fairness and according to need. Social justice requires deliberate and specific intervention to secure equality and equity (West Burnham and Chapman, 2008). We may be able to provide an equal and level playing field but we cannot guarantee equity. For example, every child needs to go to school, but we cannot guarantee that it will be the best school.

Developing a sense of social justice in Early Years is not enough. What is needed is a development of a leadership mindscape, sort of, reconfiguration of mental maps and models that may be used to make sense of how social justice, equality and equity can be made to become the warp and weft of internal school's curriculum, structure and system. Sergiovanni (2005) talks of mindscapes rather than mental maps. For him mindscapes are:

... implicit mental frames through which reality... and our place in this reality are envisioned. Mindscapes provide us with intellectual and psychological 
images of the real world and boundaries and parameters of rationality that helps us to make sense of this world... mindscapes are intellectual security blankets... and road maps through an uncertain world... (p.24)

We would suggest that effective leaders understand their mindscapes, work to systematically enrich and deepen them and use them to navigate their world. What is not so well understood is how we might develop rich and detailed personal mindscapes or what is needed to help translate mindscapes into landscapes and then move from a personal mindscape to a social imaginary of social justice (West-Burnham, 2012, personal communication).

Those leadership values underpinned by moral values of fairness and equal rights for a just society are crucial attributes to drive policy and practice forward especially in education (Coleman, 2011). Law (2006) considers that people should be encouraged to scrutinize their own beliefs and explore other points of view. Some of the skills to be cultivated may at least include the ability to:

- weigh up evidence fairly and impartially,

- make a point clearly and concisely

- look at issues from the point of view of others, and

- to question the appropriateness of, or the appropriateness of acting on, one's own feelings. (Law, 2006)

We are interested to understand how leadership in multi and mono-cultural primary schools build individual and organisational capability in these schools and how they lead with values, like equality, equity, fairness, respect and tolerance (Bell and Stevenson, 2006: 143) particularly in Early Years. As every school is different with different cultural contexts, background and history, so each, may 'interpret, articulate and implement' the concepts of equality and equity differently (Bell and Stevenson, 2006: 143). We are reminded by Gold (in Coleman and Glover, 2010: 23), that, there may be conflicting values and can we ever be sure if all leaders hold the same values in their context.

Gold (ibid) goes on to say that 'values are implicit in all of us... they guide every decision we make, even if we are not aware of this' (p. 25). So the challenge for leadership in Early Years is how best they align different values in the interest of children and educational practice. Lumby et al. (2005) showed how leaders in urban and rural organisational settings found it challenging in managing diverse staff. But with a diverse workforce come different 
skills, competences and value base that may not be so evident where there are fewer staff from different backgrounds. Lumby and Coleman's (2007) critique of diversity and equality in educational settings offers a refreshing viewpoint, stating that, supporting diversity amongst leadership may result in a 'redistribution of power' which may appear uncomfortable to a dominant group (p.79).

Norte (2001) looked at how school leaders used their power and authority to create institutional opportunities for developing positive inter-ethnic communities. He suggested the need to review organisational structure, processes, staffing, content and infrastructure and Armstrong (2009) advocates the need for effective team management. Coleman and Glover (2010: 8) develop Gosetti and Rusch's (1995) observation that looking at `society through a lens that is not that of the dominant culture can be both exciting and instructive'. This research gives us an opportunity to look reflectively and build on our knowledge and understanding to lead on issues of social justice in education (Brundrett and Anderson de Cuevas, 2008: 258 cited in Coleman and Glover, 2010: 21). We move next to looking at theories of learning as this is an important consideration for ensuring that social justice ideals are embedded in Early Years. Then we propose an analytical framework to critically review the evidence.

The varying and broader meanings of diversity in education have prompted a reconceptualisation that takes account of complex nature of differences in children $(\mathrm{Ng}, 2003$; Graham, 2007). These changes imply a move away from normative ideas that underpin categorisation of children (Petriwskyj, 2010: 196) to more differentiated pedagogies supporting children with varied characteristics (Graham, 2007). We suggest that Early Years' practitioners need to move away from surface level tinkering of the curriculum to focus on the deep hidden curriculum values and acceptance (Petriwskyj, 2010: 195). With increased migration, changes to education will have an impact on the curriculum, and it is essential that Early Years' practitioners discuss the implications of equality and equity issues on Early Years provision.

Lynn Ang (2007), reviewed the Curriculum Guidance for the Foundation Stage introduced in 2000 for all Early Years settings in England that catered for children aged 3-5 years, and commented that it 'raises questions and ambiguity' (p.188) of how diversity is addressed. She also advocates the need for deeper analysis of cultural difference if only to avoid the 
marginalisation of diversity and confer the 'privilege homogeneity through the language and culture of the dominant group' (p.188).

A poststructuralist, social stance (MacNaughton, 2005) offers us an opportunity to question our own understandings of early child education and helps us to critically reflect on the dominant discourse. We may need to go beyond the rhetoric of surface level adjustments of the EYFS (DfE: 2012) curriculum to provide education that meets the diverse needs of children with their particular cultures and ethnicities that focuses on developing their critical conscious ability. We believe that children are developing consciousness and preconceptions about diversity from birth. So focusing on interpersonal and inter-group relationships and nurturing a growing sensitivity to cultural difference (Lynn Ang, 2007: 189), may not be enough in our view, requiring in Freier's (1970) terms, a process of conscientisation that precedes any transformative process.

The process of conscientisation, is perhaps where Early Year's practitioners need to look at their educational context and learn to deconstruct and reconstruct their beliefs and practices in pursuit of the Freirian perspective of participative, democratic educational experiences for children and adults. Early Year's practitioners may need to create time and space to develop the critical consciousness in their children. This is what Oliveira-Formosinho and Araujo (2011: 228) endorse as 'experiments in democracy', where there is respect for diversity 'in all its forms'.

Norte's (2001) suggests a framework for analysing how issues of equality and equity can be developed in the curriculum, but this is the context of American schools but we feel that it is a good starting point in the English context. Norte (2001) suggests that for curriculum design and implementation, you need to take a holistic, systemic review based on these five key elements: content, process, structure, staffing and infrastructure. Weiner (2003) offers similar views suggesting the need to look at structures, space (political) and people relationships. These ideas resonate with the development of Shields' (2009) transformative leadership concept of creating spaces in which dialogue needs to occur to develop deep meaning and understanding of equality and equity on how this links with current Early Years practice. But alongside the awareness raising on equality and equity issues is the need for staff development through mentoring and coaching (Coleman and Glover, 2010), with bespoke training on cultural awareness Lynn Ang (2007) and diversity management (Lumby et al., 2005) 
Shields' (2009) view of transformational leadership is useful to reflect on in this paper as it offers a more open vision of leadership for change than proposed by transactional leadership. According to Shields (2009: 55), transactional leadership has 'a focus on exchange of mutual benefit' and transformational leadership has its 'focus on organisational improvement and effectiveness'. The latter concept calls for explicit discussion of issues of equality, equity and social justice for deep change to occur. Shields goes on to suggest the need for a systemic view of curriculum, to explicitly (our emphasis) address issues of inequity rather than talk in general terms about culture or ethnicity. Transformative leadership 'begins with questions of justice and democracy... it critiques inequitable practices and offers the promise... of better life' (2009: 55). At the heart of educational change is Shields' idea of dialogue to affect change which Friere $(1970,1998)$ calls 'dialogic relationships' (in Shields, 2009: 57). Friere argues that without such relationships, 'education acts to deform rather than to transform' (Friere quoted in Shields, 2009: 57).

Placing their values at the heart of their leadership is a mark of outstanding principals, referred to as value-driven leadership (Gold in Coleman and Glover, 2010). Many have argued (Moore et al., 2002; Gold in Coleman and Glover, 2010) that leaders' values gave the moral compass (Fullan, 2003) to help them navigate 'a hostile wider environment' (Bell and Stevenson, 2006: 150). We suggest that such a moral compass is vital to promote radical changes and improvement in Early Years at an institutional level. Developing critical consciousness of children and staff, through education, offers one such strategic direction that encompasses access and entitlement through debate on issues of diversity and equity, and the potential for wider policy refraction becomes less. The cross-cultural theory (Thomas, 2008) demonstrates the need to be cognisant of high and low context cultures and to be mindful of managing both such cultures.

From analysing the literature, three main research questions emerged:

1. What does equality and equity in the Early Years context mean?

2. How do practitioners develop the ideals of equality and equity in Early Years?

3. What are the challenges for leadership in embedding the ideals of equality and equity in Early Years? 


\section{Methodology}

We chose two types of English primary schools, those which were multi-cultural/ ethnic schools (with over $90 \%$ minority ethnic children) because their intake represented the large plural communities they were drawn from, and the other schools were mainly mono-cultural/ ethnic (less than $10 \%$ minority ethnic children) due to their under-representation from minority-ethnic intake. Most of the schools were known to the researchers because they had carried out previous research and therefore had good relationships with staff built over the years. This was seen to be strength as staff were more open and forthcoming with their discussions. The negative side of this being, that as insiders we may have inadvertently succumb to bias. But being fairly experienced researchers, we ensured that our protocol of interviews was followed rigidly, systematically and ethically and that where possible, we interviewed jointly and compared notes soon afterwards. Our driving principles of ethical educational research were of 'commitment to honesty' (Sammons, 1989 as quoted in Busher and James, 2007: 106), and 'respect for the dignity and privacy of those people who are the subjects of research' (Pring, 2000 as quoted in Busher and James, 2007: 106).

There were sixteen case study schools in total of the original sample of twenty. Each case study school was given a code, therefore, MCS1 - MC8 meant multi-cultural/ ethnic school 1-8 and MonoCS1 meant mono-cultural/ ethnic school 1-8. We interviewed sixteen Early Years leaders in the sample schools as they were the key curriculum leaders in the area being researched. We also interviewed four head teachers (two each from the multicultural and mono-cultural schools) of the sixteen schools who have had previous Early Years' experience, to get the holistic picture about the ways in which they were meeting the challenges of permeating social justice principles within Early Years. So our total sample was twenty leaders from the sixteen schools chosen. We chose questionnaires to pilot our thinking followed by interviews as this gave us an opportunity to think about educational phenomena and how to investigate them (Morrison 2007, cited in Briggs \& Coleman, 2007: $13)$.

Our interviews, defined a 'conversation with a purpose' (Dexter, 1970: 123) to share 'personal perception and experience' (Dimmock 2007, cited in Briggs \& Coleman, 2007: 63) were systematic by being carefully planned, structured and ordered. The interviews also afforded us the opportunity to '...gain insight into educational issues through understanding 
the experience of the individual' (Seidman, 1991: 7, as quoted in Coleman, 2004: 142). Considering that the field research was targeting key leaders from different schools intending to explore their perception of how social justice ideals were being implemented in the Early Years, we wanted to obtain as 'wide and as inclusive data as possible' (Denscombe, 2003 as quoted in Fogelman and Comber, 2007: 126). We assumed that the leaders in our sample schools will have a different level of understanding and experiences about social justice, so in our research design, we were careful to allow time and 'opportunity to discuss in more detail some areas of interest' (Aitken, 2011: Online) by asking more open ended questions like why? where? and when? rather than how do you...? This data and its methodological integrity provide an analytical framework and a series of tools to all stakeholders working in schools. We wanted to ensure that our methodological approach was 'open to the scrutiny and judgement of others .... and were...'subject to reflection and re-assessment by the researcher' (Morrison, 2007: 15). Moreover, we were keen to ensure that the data collected could be debated internally by the schools to enhance their innovation capacity and hopefully, 'provide a conceptual framework and an action plan for getting from questions to set of conclusions' (Yin, 1994: 2).

To ensure reliability, we asked the same questions and in the same way and we carefully prepared the piloted questions prior to the interview. Another limitation is to do with limited time for the interviews, which allowed only four head teachers from the different schools to be interviewed, while all Early Years leaders in both types of settings were interviewed. A final limitation was the study's focus on sixteen case studies resulting in limited transferability of the findings.

\section{Findings}

Based on the participants' perspectives, the findings emerged as descriptions of specific experiences of the concepts explored based on practice in each school. While there was presence of wealth of experience shared from the coded respondents, most appeared to give generic response to the questions posed. Only when probed further did the respondents articulate a deeper conceptual understanding of the issues raised. Next we present selective data on each of the three research questions for illustrative purposes given the restrictive word limitation. 


\section{What does equality and equity in the Early Years context mean?}

For some Early Year's leaders in each type of school sampled, equality and equity meant:

Meeting the needs of all the children in my class and that they all have equal opportunities in terms of access to learning and being fair (MCS1)

Everyone, staff and children has a right to be valued irrespective of background, ethnicity or ability. (MonoCS1)

Head teachers in the contrasting schools thought the following as to what equality and equity meant for them:

To be respected and valued and given the best opportunities to achieve and learn through all areas of learning. We promote equal worth of all our children and this means developing each child's self-esteem. This is done by meeting the individual needs, interests and abilities of everyone. (Head teacher, mono-cultural school, 1)

Making sure that all children in the class feel that they are being treated equally, so that they do not feel singled out in any way. Playing and learning together, understanding each other's view points and ensuring that we do this fairly and sensitively (Head teacher, multi-cultural school, 1)

Meeting individual needs was noted by all of the case study respondents and supported the concepts of the right to equal resources and fair treatment to all. The degree of equitable provision, however, could not be identified through this small scale study suggesting the need for further targeted research on policy, strategy and operational issues. Equity in most cases was described as respect and promoting human dignity that underpinned organisational ethos and culture. The head teachers supported the drive for equity and justice through formal training and mentoring programme. They also placed great value on having a formal mentor to guide staff in their initial years as Early Years leaders.

We turn next to research question about developing the ideals of equality and equity within the school structures and systems.

\section{How do practitioners develop the ideals of equality and equity in Early Years}

Equality and equity in Early Years could be developed in these ways: 
Through the topics we cover during the year that addresses each area of learning and developing innovative ways like role play to learning. (MCS5)

Our curriculum focuses on meeting the needs of all pupils, but with a particular focus on play which centres on child development and learning. We use many different games adapted from all over the world. (MCS6)

Making sure that the opportunities offered through play are linked to children's interests regardless whether they are male or female, or their background. (MCS3)

We look at equality issues through personal, social, emotional development, and equity, which to be honest I'm not sure how it's different to equality, promote it through the area of understanding the world through use of videos and have links with a school in Africa. (MonoCS6)

We use values based education where we recognise differences within the school community and the wider world and examine how everyone should have basic rights. (MonoCS8)

The head teachers said about equality and equity:

Providing children a curriculum that is based on values in order to appreciate differences and that everyone has the right to expect certain things. Our monitoring system is robust so that we can assess what we are doing well and where the gaps are. (Headteacher, mono-cultural school, 2)

Employ staff from different backgrounds if opportunity arises and using guest speakers. But the most important role I have as the head is to promote positive ethos through our vision and values and behaviour every day. All of us have to be role models for our children and this means treating everyone with respect, dignity and making sure we behave in just ways. (Head teacher, mono-cultural school, 3)

By having set guidelines to promote equality and equity otherwise these areas can be ignored. We run regular staff development on a range of issues. (Head teacher multi-cultural school, 3) 
We promote discussions where everyone's opinions are listened to and discussed. We have policies that explicitly state how the curriculum, premises and staff foster equality for all. (Head teacher, multi-cultural school, 4)

Many respondents from the sample schools were able to demonstrate examples of good practice of diversity in Early Years. Equipping young children with the critical consciousness (Friere, 1970) or reflective ability was seen by many respondents to be good skills to develop to tackle stereotypes. Leadership at all levels discussed their vision of a democratic society and how their school structures and systems would help to ensure that the vision and values (Gold in Coleman and Glover, 2010) could be carried out through in promoting Early Years practice.

Both types of schools, provided quality Early Years education and the leaders told us their practices were driven by values and behaviour that promoted equality and equity (Petriwskyj, 2010). They were focused on staff development and endeavoured to mainstream equality and equity, which meant that this was central to all aspects of policy and practice in their organisations. In addition, some of the case studies reported an example of women's network or leadership courses specifically for women or ethnic minorities. Having regular discussion of values helped some respondents to understand more fully how to value equality and equity (Lumby and Coleman, 2007; Shields, 2009).

In multicultural school Early Years settings the main advantage appears to be the diversity of population and the associated activities to enrich the curriculum. One head teacher commented why their school values of social justice and democracy underpinned his/her leadership actions and decisions. The head teachers were keen to grow their own leaders, so recognised the importance of mentoring and role models (Coleman and Glover, 2010). The Early Years leaders described the importance of understanding other languages and cultures Lynn Ang (2007) so that they could reach out to their learners and meet their individual needs better. Mentoring was evident as a deep influence on developing systems and structures that was seen to be fair and just. The collective evidence pointed to continuous communication and decision making between leaders and teachers, between teachers and parents/teaching assistants, which implied social networking that reflected a sense of working together as a group (Shields, 2009). 
2. What are the challenges for leadership in embedding the ideals of equality and equity in Early Years?

Early Years leaders identified some of the following challenges: gaining advice from specialists in the local community in relation to cultural issues (MCS7); having the time to find out the needs of the diverse groups in my class. (MonoCS7); and time and support in preparing visual resources, sign language (MCS8). The support available to EY teachers/leaders came in the form of staff in our setting from a variety of backgrounds (MCS2) and drawing on multicultural resources. Some comments regarding the personal challenges in meeting the needs of diverse children consisted of 'not knowing if what you are doing is right or not' (MonoCS4); 'Parents may have an issue learning subjects they don't feel are relevant' (MonoCS6); 'Making children aware of other cultures as they may not be educated about this - may only see stereotypes in the media' (MonoCS7) and 'harder to access sites such as temples - and not knowing where to go to get the access and information you need' (MonoCS8).

For the head teachers, their issues were:

'schools with multicultural pupil populations have more opportunities to show they are promoting equality’. (Head teacher, multi-cultural school, 4).

'Mono-cultural schools are seen to not promoting equality and equity as their population is not so diverse therefore the assumption is that we don't need to cater for anything else - this is a false view that needs to be challenge at every stage'. (Head teacher, mono-cultural school, 2).

The range of needs and issues presented in these comments is not surprising. This implies that our sample schools were at different stages of promoting their practice through the values of social justice (West-Burnham and Chapman, 2008) and moral leadership (Fullan, 2007). Every member of the respondent we interviewed valued the importance in underpinning their practice or leadership through the issues of diversity and social justice through personalised, child-centred and holistic notion of curriculum provision by all the case studies. There were formal and informal structures and systems in place in the case studies that promoted the equality and equity dimensions. Reaching out to parents was a priority for those schools who felt more explanation was needed about the values of equality and equity. Here, reputation management was important as was demonstrating leadership with values. Head teachers 
were keen to point out to us that having regular discussions of values formed part of their daily rituals to establish understanding among all staff. Acknowledgment was also made of the importance of including social justice issues in their continuing professional development as well as modelling good practice to the whole community of learners

\section{Discussion}

This study brought up the need to question and discusses how a commitment and promotion to social justice, thus equality and equity (West-Burnham and Chapman, 2008)) principles was demonstrated in the Early Years' practitioners working practices. The evidence presented showed how equality and equity was promoted through Early Years and what remained the potential challenges for leaders and practitioners. The results of the case studies analysis reveal an overall thrust to underpin practice in the Early Years through values based principles of equality and equity in both types of schools. The main strategies found in the case studies were linked with deploying diverse staff, where available in case study schools, to assist in the teaching, resource preparation and assessment of children. But Lumby et al. (2005) have pointed out the many difficult challenges this brings to the leadership team, but when it is working well, the rewards of having a diverse staff outweighs any initial doubts regarding their skills and competences in supporting learning. In the mono-cultural case studies, out-reach resourcing was the main strategy including drawing on expertise in the community on matters of diversity or cultural issues and collaborations with other head teacher network.

Our evidence reinforces the findings of the limited studies that have been conducted in the field of equality and equity (West-Burnham and Chapman, 2008). In addition, we have found that our study opened up the need for more debate about equality and equity in areas like the curriculum design, structures and systems (Norte, 2001); people-relationship (Weiner, 2003) and transformative leadership (Shields, 2009). We also found in our study that the multi-cultural and mono-cultural schools were at different stages of implementing the ideals of social justice into their curriculum, but never-the-less, were committed to the values of justice and equality through their leadership of teams. As noted in the literature section above, there are very few detailed studies that map the link between EYFS with equality and equity for direct comparisons or areas to develop further. What exists though are a few studies that look tangentially and importantly, at theories on multilingual learning in early years settings rather than what is this paper's focus (Issa and Hatt, 2013). 


\section{Implications for Early Years practice}

Equality and equity are part of the ideals of social justice and provide an impetus to overcome discriminatory behaviour (Coleman and Glover, 2010: 7) and stereotypical approaches to quality Early Years. Norte's (2001) model of curriculum reform offers one model of change where, through dialogue, staff start to see for themselves where to connect. Leaders may want to support and drive such curriculum change and implementation through sharing good practice, giving staff time for dialogue and debate and thus an opportunity for all to change the culture of the organisation. Having regular discussions of values is an important first strategy in promoting equality and equity (Coleman and Glover, 2010: 22). High success in the case studies may have shown that strong internal mentoring programme and peer group training and development. But we need to be cautious as the business of schooling has changed considerably as a result of accountability mandating a new (re)conceptualisation of the leader role in leading and managing for and with diversity (Lumby et al., 2005). This gives an entrepreneur school to take on the challenges of the new role conceptions and at looking at providing innovative responses. Equality needs to be embraced, developed and nurtured if schools of the future are to embrace innovations, requiring perhaps succession planning that deeply values and promotes the social and democratic principles of diversity, equity and social justice.

The importance of this study is that a resourceful leader (Coleman, 2011) we took risks, were open and transparent in their discussions and promoted transformative leadership behaviour which called for explicit discussion of issues of equality and equity continuously for deep change to occur (Shields, 2009). The concept of 'dialogic relationships' which Friere argues means that without such relationships, 'education acts to deform rather than to transform' (Friere quoted in Shields, 2009: 57).

Lessons learned from our study shows that practices in Early Years require a more holistic approach to planning, monitoring and evaluation. The curriculum is child-centred and the structures and systems set up should be simple to use with the head teacher providing clearly focused directions on teaching and learning strategies that ensure the values are based on equality and equity. Taking time and planning frequent communication are vital to effectiveness. It is important to recognise that we have stereotypes about leadership and about the value of types of people that prejudice our perceptions and being aware of our perceptions. Thomas (2008: 122) describes in cross-cultural theory of high and low context 
cultures: 'In low-context cultures, the message is conveyed by the words spoken. In highcontext cultures, a good deal of the meaning is implicit, and the words convey only a small part of the message.' Each of our case studies may want to reflect on their own positioning of the cross-cultural theory and see how they can become even more critically conscious in considering the importance of "values of leadership on the culture and style of the organisation' (Coleman and Glover, 2010: 56). We develop our analysis of the evidence against the model presented in Figure 1. 
Figure 1: Digrammatic plan

LEARNING STAGE - EARLY YEARS FOUNDATION STAGE (EYFS) - RE-FOCUSING OF PEDAGOGY WITH EQUALTY AND EQUITY IDEALS

\section{DIALOGUE}

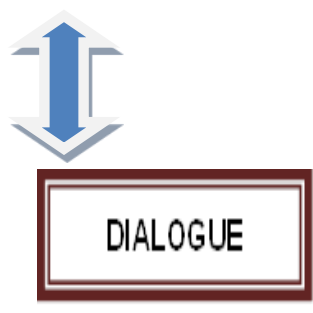

\section{DIALOGUE}

\section{DIALOGUE}

INFLUENCE STAGE - LEADERS INFLUENCE PRACTICE

VALUES-DRIVEN LEADERSHIP STAGE - RESPONSE BASED ON VALUES, BELIEFS, ETHICS AND COMMITMENT TO EQUALTY AND EQUITY

CONNECTION STAGE - STRUCTURE, PROCESSES, STAFFING, CONTENT, INFRASTRUCTURE MONITORING AND EVALUATION

REFLECTIVE STAGE - PROMOTE CRITICAL CONSCIOUSNESS IN CHILDREN AND EARLY YEARS STAFF 
In the learning stage, the content in terms of Early Years offers opportunity for a re-focusing of pedagogy through equality and equity ideals. Here, Early Years leaders continue to develop their vision through current policies and environmental scanning, to focus on identified school priorities and how to continue to implement the new EYFS curriculum. Next, the Early Years leaders may need to use their persuasive and influence skills to explain their vision in the influence stage of the plan (Weiner, 2003; Law, 2006). In this stage of the cycle, the development of inclusive staff cultures is very important. This is likely to be more important to ensure that new appointments are committed to the schools' mission social justice. The commitment to equality and equity and values-driven philosophies may prove to be central for successful implementation and embedding of Early Years in the values-driven stage of the cycle.

The connection stage arguably allows time, space and people to be organised and reconfigured in order for the implementation stage where curriculum planning takes place. Although we have not discussed in any detail the involvement of the community, its involvement seems a strong feature of good practice. Indeed, working beyond school boundaries is a pre-requisite if children are to achieve the Early Learning Goals by the end of the reception stage. The reflective, monitoring stage aims at charting progress on the action plans and priorities and the evaluation stage completes the cycle for next strategic intent and action. This is a crucial outcomes stage where we believe there is probable potential to develop the critical consciousness (Freire, 1998) in children modelled by staff and leadership. We are aware that to accomplish Early Years reform these equity reforms will require a new kind of leadership, one that requires resourceful leadership skills (Coleman, 2011), imagination, difficult dialogues and courageous actions (Shields, 2009). Transformative leadership through dialogue at every stage of the cycles mentioned in our plan may help to promote justice for the entitlement of every child and family, and of society as a whole. This may be a simplistic model but it offers an opportunity for Early Years leaders to debate about their school's structures and systems in their own context and community settings.

\section{$\underline{\text { Implications for research }}$}

Our findings indicate that Early Years through the new curriculum implementation is at a start of its change journey and the notion of equality and equity may take time to implement and embed. But it is likely that in good schools, structures and systems are already in place 
to gently ease such change, but the impact of such initiatives need researching further. Each case study school may differ to some degree based on the drive from the leadership. For example, it may be that some of the multicultural schools had greater advantage in the practice of embedding equality and equity, whereas some of the mono-cultural schools had to be more creative and be more resourceful in its implementation. Our findings also suggest that the mono-cultural schools could well benefit from twinning, clustering, and other forms of existing collaborations to share good, innovative practice. Here, both types of schools gain mutual benefit and this could be researched further through specific cases studies on how equality and equity is implemented in practice compared to theory. It is important to state here that none of the case studies used in our study disadvantaged children's education whether they had clearly thought through or not the implications of permeating social justice principles. All of them believed in and actively promoted the principles of social justice and equal rights.

We are left with more questions than answers like, what are the characteristics of multicultural schools that might influence the practice of promoting social justice more than mono-cultural schools? Does the school context make a bigger difference than promoting equality and equity alone? How do we know that using professional development for specific groups may lead to modelling good practice whether in multicultural or mono-cultural schools? Should we acknowledge the importance of including social justice issues in training for educational leaders and how do we know it may help model good practice? A final implication is that, should leadership at all levels become more risk takers and embrace the advantages of diverse workforce, even though managing and leading diverse staff has its own major challenges (Norte, 2001; Lumby et al., 2005).

\section{Conclusion}

The most important contribution of the study is the reflective evidence showing that Early Years is permeating through the social justice principles of equality and equity can be clearly demonstrated. A critical feature emerges from our data, in that, good Early Years practice is child -centred and underpinned with democratic and social justice values. The discussion suggested that innovative early years practice in the case studies may vary, but fostering and developing a culture of change that embraces equality and equity in Early Years are more likely to be successful. Three central perspectives are produced. First, the Early Years offers a distinct and rare opportunity to embed the principles of equality and equity through play 
and promoting learning through first hand pedagogical activities. It also means having regular discussions of values of social justice and moral leadership through establishing understanding among staff, parents and community. In this way, the management of change may seem to be less conflicting if ideas from all are considered. Second, it is imperative that leaders look at their existing policy and structures to establish and support implementation of equality and equity without making it appear to be tokenistic. Third, it is important to take into account the dynamic nature of change process itself. Our study shows the importance of examining the meaning of equality and equity and how it can be implemented in Early Years, because in a situation of change, these are concepts with much explanatory power.

\section{Acknowledgements:}

The authors would like to thank all the staff in the sample schools for their valuable thoughts and comments. They would also like to thank their respective universities for their support.

\section{References:}

Aitken, H. (2011) Conducting face-to-face interviews.

http://www.aetz.org/files/documents/Interview\%20Techniques.pdf. (Accessed 25 ${ }^{\text {th }}$ March 2013).

Armstrong. M. (2009) Armstrong's Handbook of management and leadership: A guide to managing for results. London: Kogan Page.

Bell, L. and Stevenson, H. (2006) Citizenship and social justice: Developing education policy in multi-ethnic schools, in L. Bell and H. Stevenson (eds). Education Policy: Process, Themes and Impact. London: Routledge.

Burchardt, T. (2007) Foundations for measuring equality: A discussion paper for the Equalities Review. http://sticerd.lse.ac.uk/case. (accessed 15 ${ }^{\text {th }}$ April 2013).

Busher, H. and James, N. (2007) Ethics of research in education in Briggs, A.R.J. and Coleman, M. (eds.) Research Methods in Educational Leadership and Management. London: Sage Publications. pp. 106-122.

Coleman, M. and Glover, D. (2010) Educational Leadership and Management: Developing insights and skills. Maidenhead: Open University Press and McGraw-Hill Education. Coleman, A. (2011) Resourceful leadership: how directors of children's services lead to improve outcomes for children. BELMAS Annual International Conference 2011, 8th - 10th July 2011, Wyboston Lakes, Bedfordshire, UK. 
Department for Children, Schools \& Families (DCSF) (2008) Practice Guidance for the Early Years Foundation Stage. London: DCSF

Department for Education (DfE) (2011) The Tickell Review - background. London: DfE http://www.education.gov.uk/tickellreview (accessed 15 ${ }^{\text {th }}$ April 2013).

Department for Education (DfE) (2012) Statutory Framework for the Early Years Foundation Stage (EYFS). London: DfE.

http://media.education.gov.uk/assets/files/pdf/e/eyfs \%20statutory\%20framework\%20march\% 202012.pdf (accessed April 2013).

Dexter, L. (1970) Elite and Specialized Interviews. Evanston, IL: North Western University Press.

Dimmock, C. (2007) Cross-Cultural Differences in Interpreting and Conducting Research in Briggs, A.R.J. and Coleman, M. (eds.) Research Methods in Educational Leadership and Management. London: Sage Publications. pp. 53-68.

Fiske, S.T. and Lee, T.L. (2008) Stereotypes and prejudice create work-place discrimination, in A.P. Brief (ed.) Diversity at Work. Cambridge: Cambridge University Press.

Fogelman, K. and Comber, C. (2007) Surveys and Sampling in Briggs, A.R.J. and Coleman, M. (eds.) Research Methods in Educational Leadership and Management. London: Sage Publications. pp. 125-141.

Friere, P. (1970) Pedagogy of the Oppressed. New York: Heder \& Herder.

Friere, P. (1998) Pedagogy of Freedom: Ethics, Democracy, and Civic Courage. Lanham, MD: Rowman \& Littlefield.

Fullan, M. (2003) The Moral Imperative of School Leadership. London: Sage.

Fullan, M. (2007) The New Meaning of Educational Change. $4^{\text {th }}$ edn. Teachers College, Columbia University: Teachers College Press.

Gardner, H. (2006) Five minds for the future. Harvard University: Harvard Business Press. Gold, A (2010) Leading with values in Coleman, M. and Glover, D. (2010) Educational Leadership and Management: Developing insights and skills. Maidenhead: Open University Press and McGraw-Hill Education. pp. 23 - 39.

Gosetti, P. and Rusch, E. (1995) Re-examining educational leadership: Challenging assumptions, in D. M. Dunlap and P.A. Schmuck (eds) Women Leading in Education. Albany, NY: State University of New York.

Graham, L. (2007) Done in by discourse ... or the problem/s with labelling. In Schools and diversity. 2nd edn. M. Keefe and S. Carrington (eds). Frenchs Forest: Pearson. pp. 46-53. 
Heifetz, R., Grashow, A. and Linsky, M. (2009) The Practice of Adaptive Leadership, Boston, MA: Harvard Business Press.

Isaacs, S. (1933). Social development in young children. London: Routledge \& Kegan Paul. Issa, T. and Hatt, A. (2013) Language, culture and identity in the early years. London: Bloomsbury.

Jehn, K.A., Greer, L.L. and Rupert, J. ( 2008) Diversity, conflict and their consequences, in A. P. Brief (ed.) Diversity at Work. Cambridge: Cambridge University Press.

Law, S. (2006) The War for Children's Minds. London: Routledge.

Lumby, J., Harris, A., Morrison, M., Muijs, D., Sood, K., Glover, D., Wilson, M. with Briggs, A.R.J. and Middlewood, D. (2005) Leadership development and diversity in the learning and skills sector. London: LSDA.

Lumby, J. and Coleman, M. (2007) Leadership and Diversity: Challenging Theory and Practice in Education. London: Sage.

Lumby, J. (2010) Leadership for diversity and inclusion. In The Principles of Educational Leadership \& Management. 2nd edn. T. Bush., L. Bell, and D. Middlewood (eds). London: Sage. pp. 145-57.

Lynn Ang, L. Y. (2007) Cultural diversity and the Curriculum Guidance for the Foundation Stage in England, European Early Childhood Education Research Journal, 15(2): 183-195 http://dx.doi.org/10.1080/13502930701321428 (accessed 11th February 2013).

MacNaughton, G. (2005) Doing Foucault in early childhood studies. Applying post structural ideas. London and New York: Routledge.

Moore, A., George, R. and Halpin, D. (2002) The development role of the headteachers in English schools: management, leadership and pragmatism, Educational Management and Administration, 30(2): 175-88.

Morrison, M. (2007) What do we mean by Educational Research in Briggs, A.R.J. and M. Coleman (eds.) Research Methods in Educational Leadership and Management. London: Sage Publications. pp. 13-36.

Ng, R. (2003) Towards an integrative approach to equity in education. In Pedagogies of difference: Rethinking education for social change. P. Trifonas (ed). New York, NY: Routledge Falmer. pp. 206-19.

Norte, E. (2001) 'Structures beneath the skin:' How school leaders use their power and authority to create institutional opportunities for developing positive inter-ethnic communities. Journal of Negro Education, 68(4): 466-485. 
Oliveira-Formosinho, J. and Araujo, S. B. (2011) Early education for diversity: starting from birth. European Early Childhood Education Research Journal, 19(2): 223-235

http://dx.doi.org/10.1080/1350293X.2011.574410 (accessed 6 ${ }^{\text {th }}$ February 2013).

Petriwskyj, A. (2010) Diversity and inclusion in the early years, International

Journal of Inclusive Education, 14:2, 195-212 http://dx.doi.org/10.1080/13603110802504515 (accessed $6^{\text {th }}$ February 2013).

Sergiovanni, T. (2005) Rethinking leadership: a collection of articles. CA: Corwin Press.

Shields, C. M. (2009) Transformative Leadership: A Call for Difficult Dialogue and

Courageous Action in Racialised Contexts, International Studies in Educational

Administration, 37(3): 53-68.

Thomas, D. (2008) Cross-cultural Management: Essential Concepts. $2^{\text {nd }}$ edn. Thousand Oaks, CA: Sage.

Weiner, E.J. (2003) Secretary Paulo Freire and the Democratization of Power: Toward a Theory of Transformative Leadership, Educational Philosophy and Theory, 35(1): 89-106.

West-Burnham, J. and Chapman, C. (2008) Social justice in Education. London: Continuum. Yin, R.K (1994) Case Study Research: Design and Methods. Thousands Oak: Sage. 